\title{
Acoustic Detection of Tagged Angelsharks from an Autonomous Sailboat
}

\section{J. Cabrera-Gámez, A. C. Domínguez-Brito, F. Santana-Jorge, D. Gamo, D. Jiménez, A. Guerra and J. J. Castro}

Instituto Universitario SIANI (www.roc.siani.es), Departamento de Informática y Sistemas (www.dis.ulpgc.es)

Servicio Integral de Tecnología Marina (www.sitma.ulpgc.es Instituto Universitario ECOAQUA (ecoaqua.ulpgc.es)

Universidad de Las Palmas de Gran Canaria (www.ulpgc.es), Spain

in: Silva M., Luís Lima J., Reis L., Sanfeliu A., Tardioli D. (eds) Robot 2019: Fourth Iberian Robotics Conference. ROBOT 2019. Advances in Intelligent Systems and Computing, vol 1092. Springer, Cham.

$$
\text { https://doi.org/10.1007/978-3-030-35990-4_24 }
$$

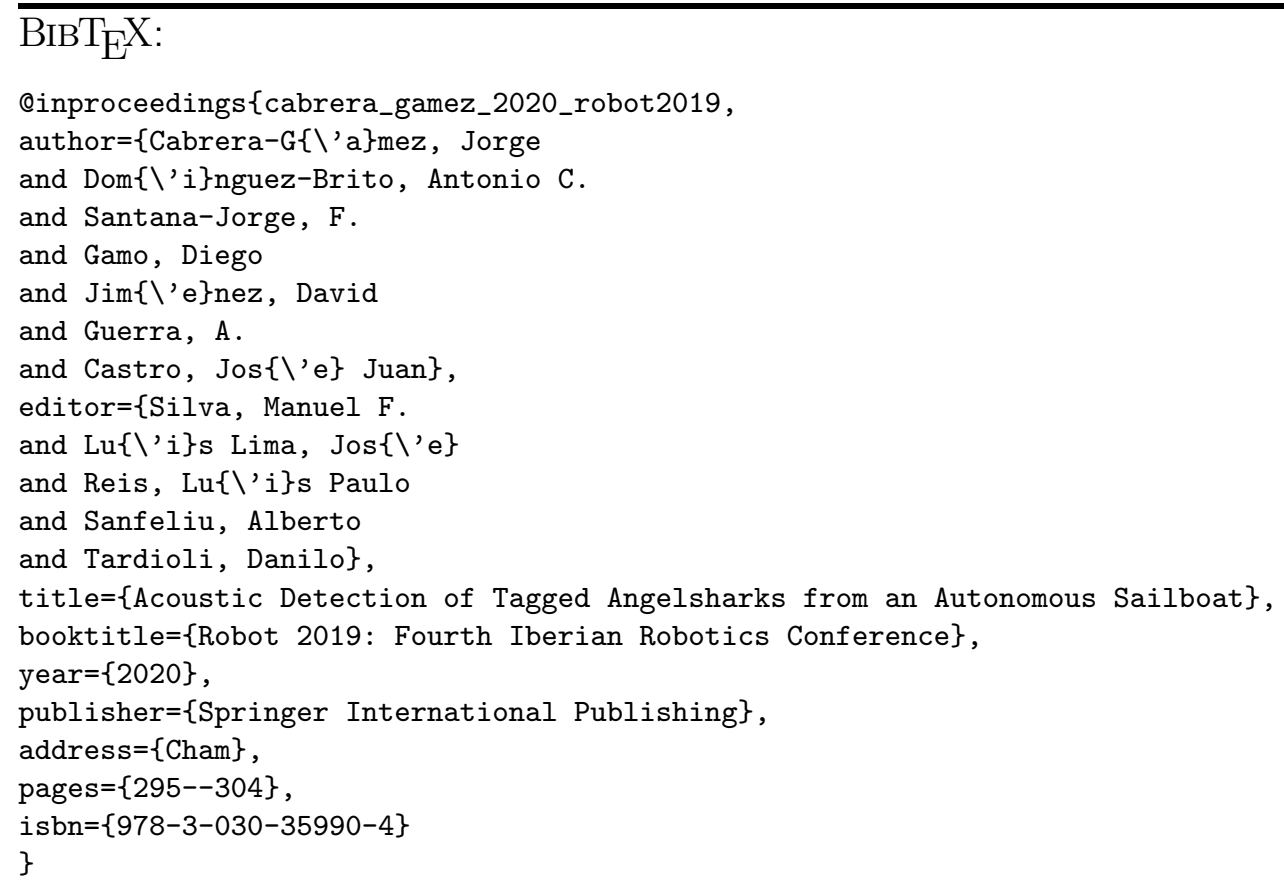

Copyright (C) 2020 Springer Nature Switzerland AG. (www.springer.com)

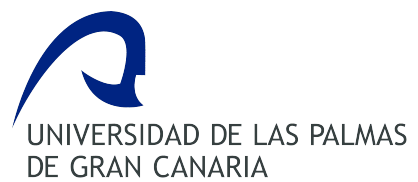




\title{
Acoustic detection of tagged Angelsharks from an autonomous sailboat
}

\author{
J. Cabrera-Gámez ${ }^{\dagger \ddagger}$, A. C. Domínguez-Brito ${ }^{\dagger \ddagger \S}$, F. Santana-Jorge ${ }^{\ddagger}$, D. Gamo ${ }^{\ddagger}$,

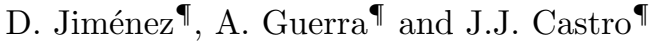 \\ ${ }^{\dagger}$ Instituto Universitario SIANI (www.siani.es) and Departamento de Informática y Sistemas \\ (www.dis.ulpgc.es), Universidad de Las Palmas de Gran Canaria (www.ulpgc.es), Spain \\ ‡ Servicio Integral de Tecnología Marina (www.sitma.ulpgc.es), Universidad de Las Palmas de Gran \\ Canaria (www.ulpgc.es), Spain \\ ๑ Instituto Universitario ECOAQUA (http://ecoaqua.ulpgc.es), Universidad de Las Palmas de \\ Gran Canaria (www.ulpgc.es), Spain \\ $\S$ Corresponding author's email: antonio.dominguez@ulpgc.es
}

\begin{abstract}
Autonomous sailboats are silent surface vehicles which are well suited for acoustic monitoring. The integration of an acoustic receiver in an unmanned surface vehicle has a large potential for population monitoring as it permits to report geo-referenced detections in real time, so that researchers can adapt monitoring strategies as data arrive. In this paper we present preliminary work, done on the framework of ACUSQUAT project, to explore the usage of an acoustic receiver onboard a small ( $2 \mathrm{~m}$ length-over-all) autonomous sailboat in order to detect the presence of tagged adult exemplars of angelshark (Squatina squatina), the target species in ACUSQUAT, in certain areas which have demonstrated that this approach is feasible. Results obtained in simulation and during field trials are presented.
\end{abstract}

Keywords: autonomous sailboat, autonomous navigation, sensor integration, acoustic receiver, accoustic tag detection, angelshark (Squatina Squatina)

\section{Introduction}

Angelsharks (Squatina squatina, a specimen shown in Fig. 1㑑) were common and abundant elasmobranchs along the European Atlantic coast and also in the Mediterranean Sea. This species, alike some other Squatinidae, have suffered from intensive fishing, both because they were captured intentionally or they were a common by-catch in trawling fishing practices, with the consequence of very strong reductions in population or even its disappearance in many areas. All this has driven Squatina squatina to be included in the Red List of Threatened Species by the International Union for Conservation of Nature (IUCN) as in critical danger of extinction [7. Moreover, very recently, June $5^{\text {th }} 2019$, the Spanish Government has officially included Squatina squatina and two other Squatinedae spp., Squatina oculata and Squatina aculeata, in the Spanish Catalog of Threatened Species as in danger of extinction. 


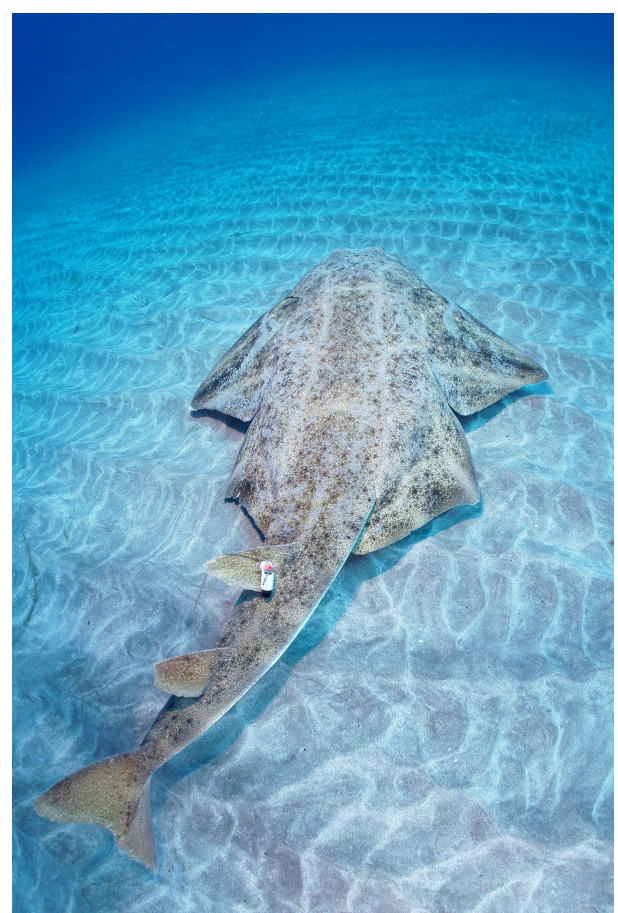

(a)

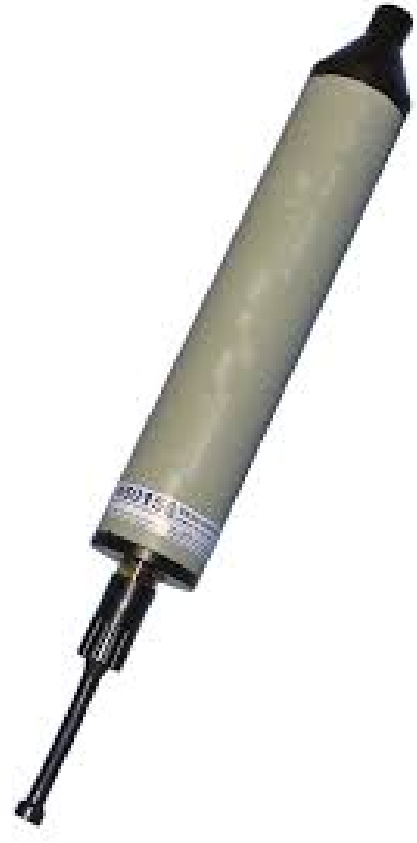

(b)

Fig. 1: a) Tagged angelshark over a sandy bottom. Tag is appreciable on the main dorsal fins. Picture courtesy of Mike J. Sea and the Angel Shark Project. b) Vemco's VR2C mini acoustic receiver.

The Canary Islands archipelago is one of the few locations in the EU (European Union) where the population of Squatina squatina is still well preserved [5, but its conservation is not exempt of problems derived from touristic activities, e.g. maritime traffic, sportive fishing or intense utilization of beaches, in some areas.

Conservation efforts addressing the recovery of marine endangered species require a careful knowledge of species-specific daily and seasonal patterns of habitat occupation, population structure and which environmental factors influence or determine the preference of this species for certain areas. Acoustic tracking has shown to be an effective methodology to research these aspects with other species and it is currently being implemented for Squatina squatina in Canary Islands.

The utilization of autonomous vehicles for acoustic registration started more than ten years ago with the works of J. Dobarro and collaborators 3, exploring the feasibility of using an autonomous underwater vehicle (AUV) to acoustically track tagged Atlantic sturgeons in the Hudson River. Lin and collaborators [4] have discussed the utilization of a stereo hydrophone system for tracking a tagged 
leopard shark. A recent review on the utilization of unmanned vehicles for the detection and monitoring of marine fauna can be found on 9 .

Unmanned sailboats are slowly revealing their potential as interesting costeffective platforms for oceanographic research [10] 22. In the specific realm of acoustic tracking, these acoustically silent vessels have already demonstrated their utility, e.g. [6], and how they can be used to complement a moored network of detectors in very interesting ways. It is normally unfeasible to cover all the area under study with the number of available receivers located at a few, strategically selected, locations leaving the rest of the area uncovered. Additionally, a network of acoustic receivers do not usually provide data in real-time, but when receivers are recovered. Using one or several vehicles, acting as mobile receivers, it is possible to extend the detection coverage using different strategies.

Recently, this approach has been extended to a fleet of vehicles in order to achieve wider coverage and/or improve localization. In [11] it is described, as a proof of concept, the utilization of heterogeneous fleet, including unmanned and manned surface vehicles and AUVs, to acoustically track tagged fishes.

This paper first describes the main characteristics of the elements required for setting up an acoustic tracking network and its integration in the A-Tirma autonomous sailboat. Final sections are devoted to illustrate results obtained in simulation and during the first field trials.

\section{Material and Methods}

An acoustic tags receiver (Fig. 11/D) have been integrated in A-Tirma G2 (ATirma, for short), a two-meter length autonomous sailboat provided with two wing sails (a more detailed description can be found in 1]). The boat is shown in Fig. 细 and Fig. 2| 2 displays an underwater view of A-Tirma towing the receiver.

The acoustic receiver integrated into A-Tirma was a Vemco's VR2C mini receiver. This receiver's dimensions are: $317 \mathrm{~mm}$ length, $54 \mathrm{~mm}$ diameter, 0.7 $\mathrm{kg}$ in-air weight. It operates at $69 \mathrm{kHz}$ and has a maximum depth of $25 \mathrm{~m}$. It lacks an internal battery, so it must be powered through the towing cable, but power demands are modest and flexible (line voltage 10-32 VDC, @12V, record mode $<1 \mathrm{~mA}, 3-15 \mathrm{~mA}$ during communications). The VR2C mini has an internal memory (16 Mbytes) capable of storing nearly 1.6 million detections. A bidirectional serial interface, either RS-232 or RS-485, runs also over the cable. Using this interface, the receiver can be reconfigured at anytime from the host system. If properly configured, the receiver can report detections in real-time to the sailboat controller where, using the GNSS receiver available on board, they can be geo-localized and reported.

Adult angelsharks are being tagged with Vemco's V9-2L $69 \mathrm{kHz}$. coded tags (length: $29 \mathrm{~mm}$.; diameter: $9 \mathrm{~mm}$.; weight in water: 2.9 gr. and power output: 146 $\mathrm{dB}$ re $1 \mu \mathrm{Pa} @ 1 \mathrm{~m})$. These tags' weight and dimensions are perfectly compatible with the tagging ethics standards. Programmed with a nominal period of 180 seconds, the expected battery lifetime is 912 days, permitting to extend the study over several seasonal cycles. 


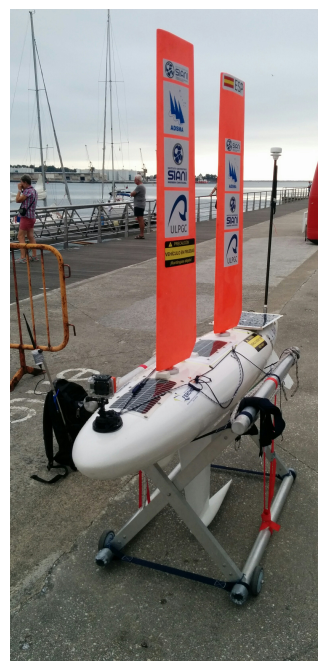

(a)

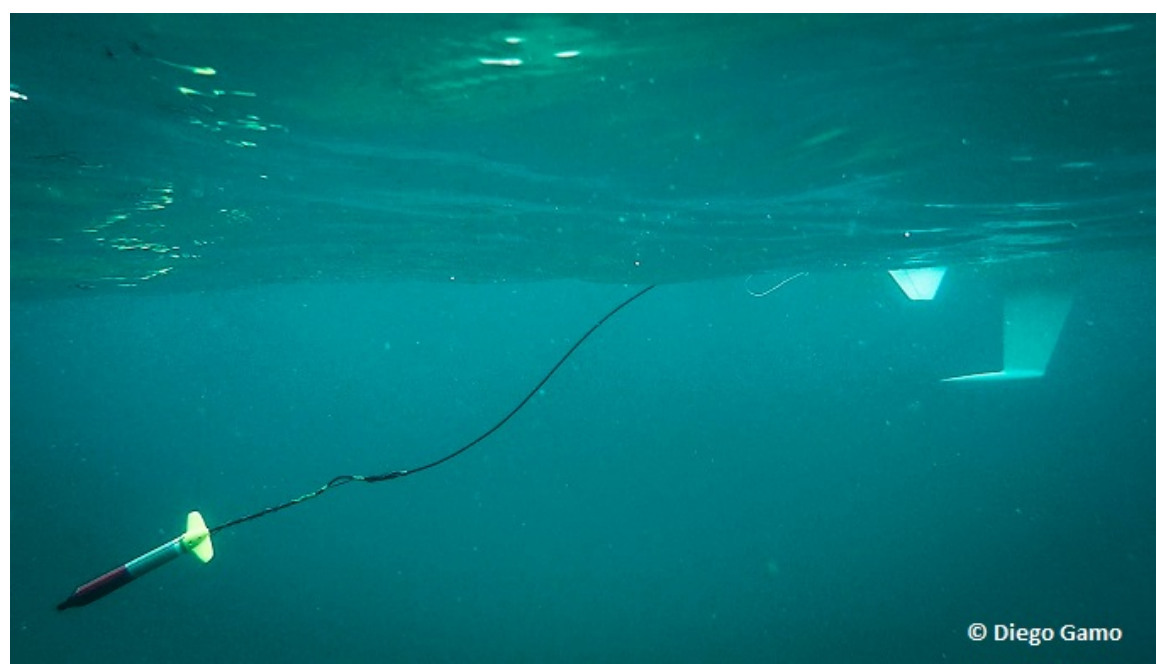

(b)

Fig. 2: a) A-Tirma G2. b Underwater view of the receiver being towed by the sailboat. The sailboat's keel and one of the skegs are visible at the right of the picture.

A-Tirma is equipped with a communications infrastructure consisting of three types of communication devices. Namely, one for short range communications: a XBee radio link. And, two for long range communications: a 3G/GPRS link for areas where mobile telephony communication services are available, and a satellite Iridium SBD transceiver for high seas when no other way of long-distance communication is possible. Through those three links the sailboat can be supervised and monitored remotely during a real navigation using a software graphical interface. In addition, a public web tracker of the boat is available, where the trajectory and behavior of the boat can be openly published during on-field navigation. A detailed description of A-Tirma's communication infrastructure can be found in [8. In relation to the operation of the acoustic receiver during a navigation session, it is possible to activate/deactivate the receiver remotely using the graphical interface. Once the receiver is active, its operational status can be monitored in real-time through the graphical interface. Also, when active, if any animal tag is detected, the detection is registered on secondary memory on the boat, and on the graphical interface, the position of the boat where the detection was verified is also shown. Fig 3 shows a snap-shot of A-Tirma's graphical interface, where we can see how the acoustic sensor information has been integrated graphically. This figure also shows how detections are displayed on the interface along with operational status information. From a hardware point of view, Fig. 4 depicts, in a deployment diagram, how Vemco's VR2C acoustic receiver has been integrated in the boat. As we can note in the figure the receiver 


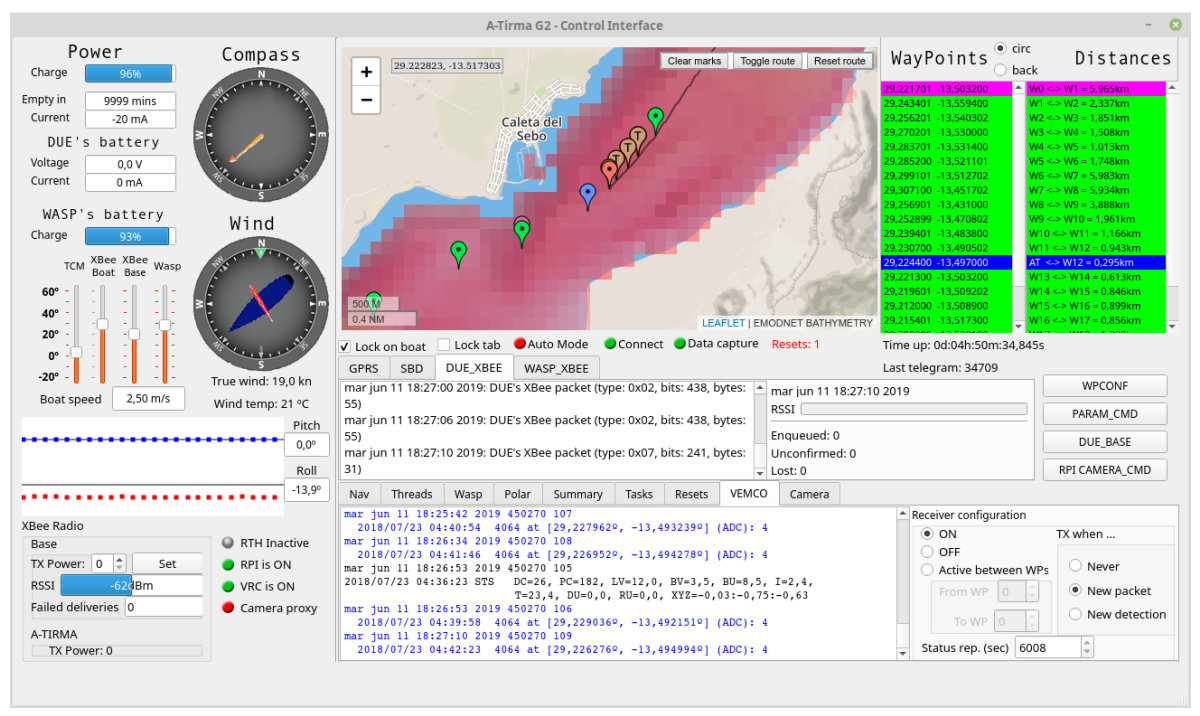

Fig. 3: A-Tirma G2's graphical interface. On the map area: the blue icon is the current waypoint the boat is navigating to, the red icon is the boat itself, green icons are the rest of waypoints which conform the route followed by the boat. On the right side of the map all waypoints coordinates are listed, and the current one is also highlighted in blue. Finally, light brown icons signed with a "T" are acoustic tag detections performed by the boat using the Vemco's VR2C acoustic receiver. In addition, there is a tab in the inferior part of the interface, tab "VEMCO", which presents, when the receiver is active, operational status information (text in black), and data (text in blue) about the tags as they get detected in real-time during the navigation.

is connected via an asynchronous serial link (RS-232) to A-Tirma's main system controller on board.

The receiver is towed using a reinforced 10 meter-long cable. To avoid cable torsion, a two-part stabilizer (visible in yellow in Fig. 22p has been designed and manufactured by 3D printing. This part also offers a secure cable locking point so that the towing tension is not directly supported by the locking sleeve of the receiver connector.

\section{Simulation results and field experiments}

Extensive simulation tests have permitted to verify the correct integration of the receiver in the control and communication architecture of the boat. These tests have been carried out first with the real receiver in the hardware loop and later with a simulated device written as an extra simulator's software module. This procedure allowed to validate the simulated receiver. Additionally, the simulator module permits to select the motion patterns that the simulated tagged animals 


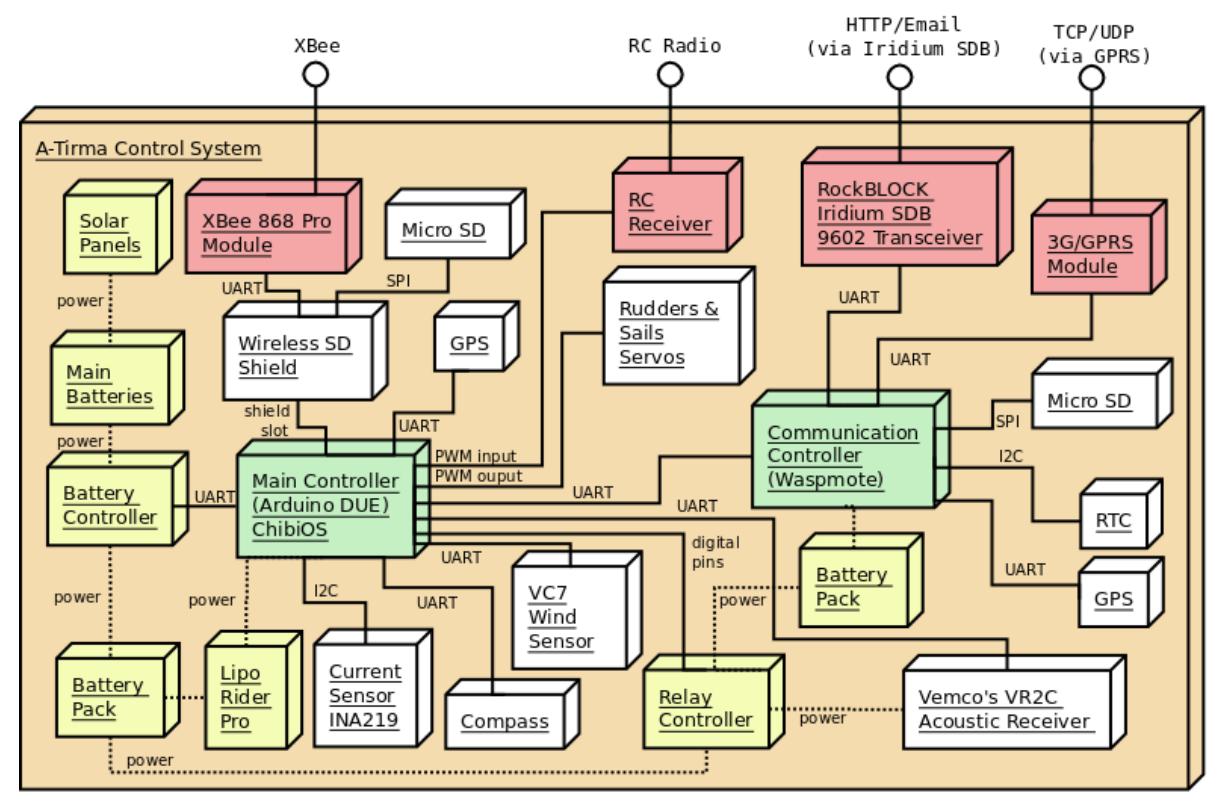

Fig. 4: A-Tirma G2's deployment diagram. Vemco's VR2C acoustic receiver (bottom-right corner) has been integrated on the main controller through an asynchronous serial (RS-232) connection.

will exhibit during a simulation, and also to constraint their displacements to certain geographical zones. In particular, for a given animal, its pattern of movement is restricted to a circular area centered on a given geographical location, which is the starting position of the animal when the simulation is started. In addition, some other parameters define the animal's movement pattern, namely: maximum reachable depth, maximum speed, and maximum heading change (at each simulation step, a positive or negative heading change is calculated randomly limited by this value). Moreover for each animal, some other values define how the animal's simulated tag behaves, such as, its emission period, whether it is a high transmission power tag or not, and if it is equipped with a pressure sensor or not. In this simulation the sound has been modelled in a very simple way, considering a constant sound velocity. As already shown, Fig. 3 displays the reception of status and detection packets as they are shown on the control graphical interface during a navigation session, whether real or simulated.

Some field trials have been carried out to test the feasibility of using a receiver onboard the A-Tirma sailboat. This study has been developed in parallel to animal tagging, which is still underway. These experiments have focused on determining the best placement of the receiver in the A-Tirma in order to maximize tag detection probability with a minimal impact on sailboat's maneuverability.

The receiver has an omnidirectional reception sensibility pattern centered around its longitudinal axis. Thus, the best detection results are expected with 
the receiver close to a vertical position with the hydrophone facing downwards, specially if the receiver is being towed near the surface and the target species is benthonic, as in our case.

The placement explored so far with the A-Tirma has consisted in towing the receiver at the extreme of a 10-meters long cable secured at the stern of the sailboat. The receiver has been ballasted carefully to achieve a towing depth of approximately $2 \mathrm{~m}$ and a characteristic pitch around $30^{\circ}$, as illustrated in figure 2/b. This disposition has not affected in any significant manner ship's maneuverability under the testing conditions, which have been characterized by low wind speed. However, increased drag is likely to be expected at higher wind speeds.

The field tests performed in order to study the reception and detection of tags towing the receiver from a boat were carried out in the area of Puerto Rico in the island of Gran Canaria, Spain (illustrated in Figures 5 and 6). Four acoustic tags were moored in a line, situated each at different depths. The four tags correspond with tag identifiers 4064, 20255, 20254 and 4063, situated respectively at 1, 3.5, 6 and 8.5 meters from sea bottom. The first three tags emit their ID in low power mode, while the 4063 emits in high power mode. Low power mode reduces the utilization of energy, with a positive effect on the longevity of the tag, at the cost of a possible reduction in range detection, i.e. pinging is done at a reduced intensity. Additionally, tags 4063 and 4064 also provide pressure information, from which we can derivate depth. In Fig. 6 we can observe how many times and where each one of them was detected during the experiment. As expected, tag 4063 was detected more times since it is a high power tag. During the field tests, a fifth tag (tag no. 25639) was detected three times (Fig. 6). This was a tag previously deployed in the area during animal tagging. This configuration of four-tags were situated in two locations, namely, locations L1 and L2 displayed in Fig. 5. the depth in both locations was of about 26.5 and 29.5 meters respectively. Despite the high maritime traffic of the area, these experiments were carried out in this zone as this is the focal area for the ACUSQUAT project where some angelsharks exemplars are being tagged.

A relevant qualitative conclusion drawn from these experiments has been that the orientation of the receiver relative to the tag position has an important influence in the probability of detecting a tag emission. This is evident from inspection of Fig. 5. More precisely, when the boat is moving away from the tags and the receiver gets oriented towards them (the moving away green arrow from location L2 in the figure) the probability of detection is high and many tags emissions are detected. On the contrary, when the boat goes toward the tags (indicated with the green arrow going towards L2 in the figure), there are no detections until it gets quite close to tags in location L2. In this second case, the orientation of the receiver, as it gets towed, has the hydrophone looking in the opposite direction to where the tags are situated. This asymmetry in detection vanished when towing was stopped and the receiver recovered a vertical orientation or, when the receiver was not towed directly towards the position of the tags, as was the case when tags were moored at L1. As conclusion, keeping 


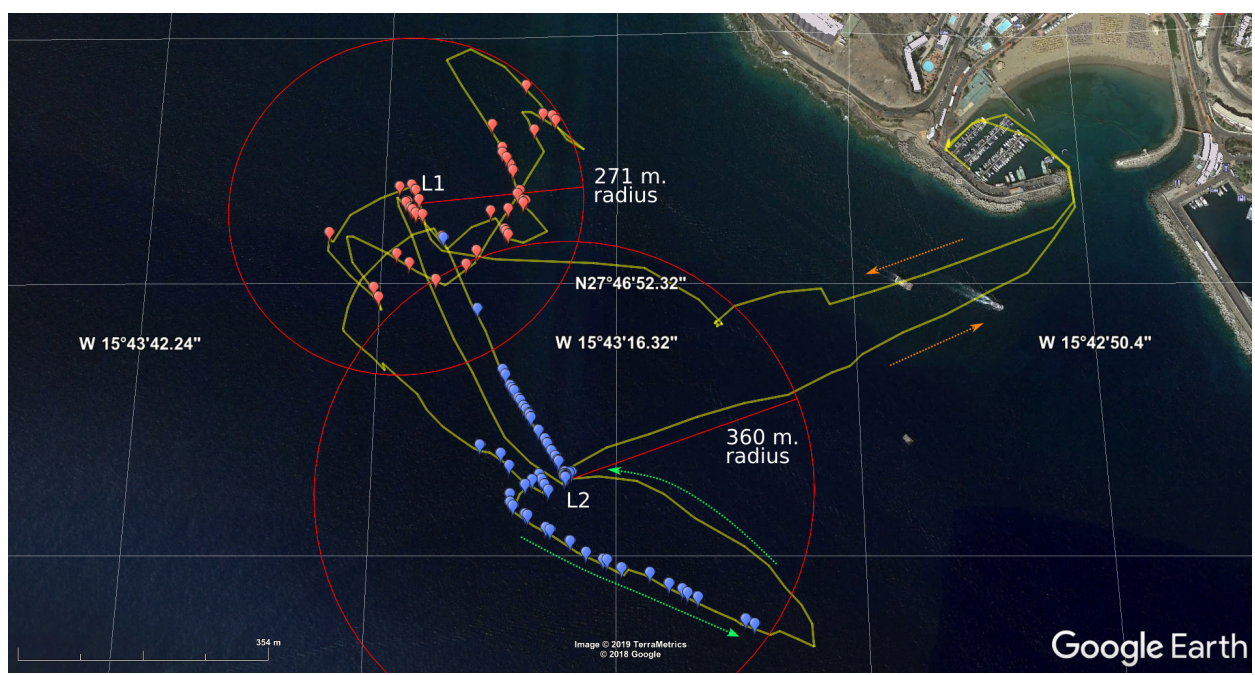

Fig. 5: Field tests for checking the reception and detection of acoustic tags performed in the area of Puerto Rico, Gran Canaria, Spain. The trajectory of the boat towing the receiver is shown in yellow. Red icons show tag detections when the four-tag pattern was situated in location L1. Blue icons correspond to detections with the four-tag pattern in location L2.

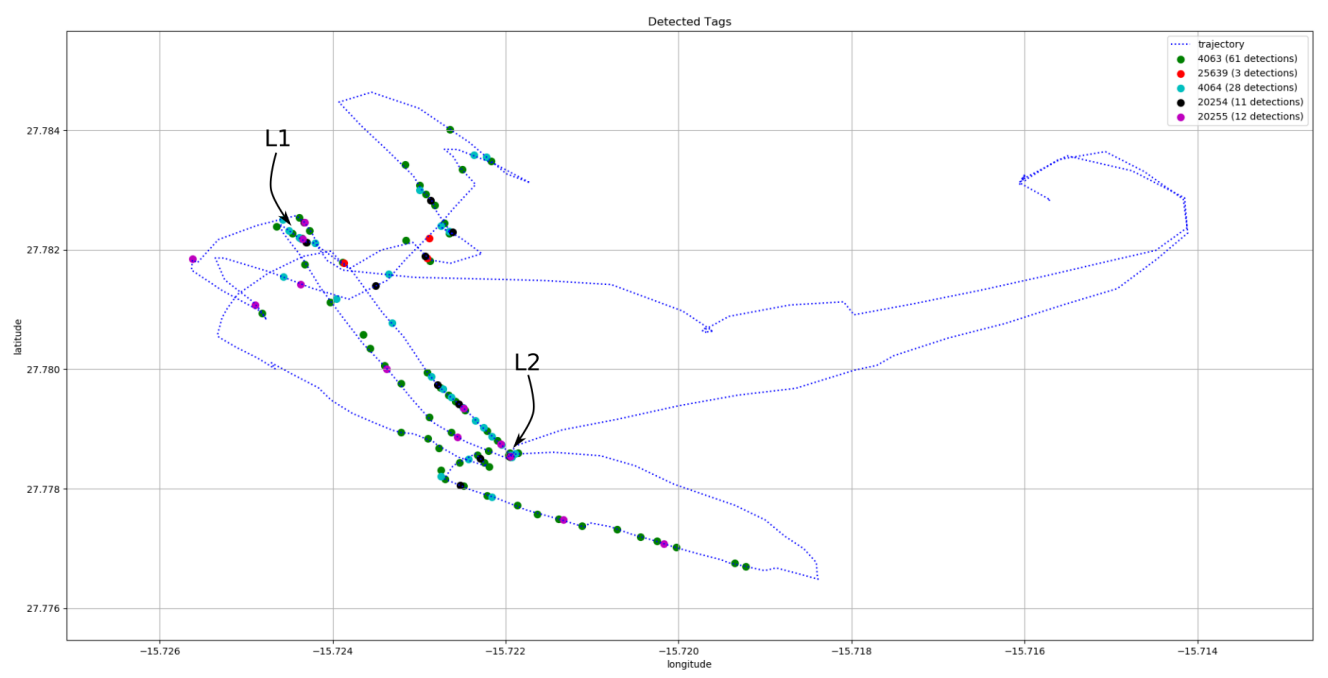

Fig. 6: Detected tags corresponding to the field tests shown in Fig. 5

the receiver vertically orientated seems more adequate to maximize tag detection probability. 


\section{Conclusions}

In a first stage, we have integrated a Vemco VR2C mini receiver into the control and communication layers of A-Tirma autonomous sailboat. Extensive tests have been run in simulation to verify the stability and responsiveness of the control and communication system software. Also, first field trials have been developed to characterize the detection probability with range. These experiments have shown that the sailboat is capable of towing the receiver even with faint winds, even though the absolute orientation of the receiver during towing needs to be optimized. More in-depth testing is planned to study the influence of the environment (bathymetry, distance to shore, ship traffic, etc) in detection probability with range, and specially for evaluating how the quality of tag detections get influenced by tag's orientation, receiver's distance-from-tag, orientation and depth, and also by boat's direction and speed.

Future work will address exploring alternative ways of installing the receiver. One attractive possibility is removing the towing fixation point from the stern to a point located underwater in the bulb at the deeper extreme of the keel. This will allow to reduce the cable length, for the same towing depth, with a positive impact in the maneuverability of the boat. Another possibility we aim to explore is fixating the receiver, close to a vertical position, as suggested above, at the deepest available placement on the keel. This option would eliminate also the drag induced by the towing cable. However, under the conditions imposed by A-Tirma dimensions, it is foreseen that this placement will produce a significant reduction in range detection due to the noise induced by wind, waves and hull motion.

\section{Acknowledgements}

This research has been partially funded by Loro Parque Fundation through project BioACU and Fundación Biodiversidad (Spanish Ministry for Ecological Transition) through project: "ACUSQUAT: Seguimiento acústico del comportamiento del angelote (Squatina squatina) en áreas críticas de conservación" (Acoustic tracking of Angelshark (Squatina squatina) behavior in critical areas of preservation). Reference CA_BT_BM_2017.

\section{References}

1. Domínguez-Brito, A.C., Valle-Fernández, B., Cabrera-Gámez, J., Ramos-de Miguel, A., García, J.C.: A-tirma g2: An oceanic autonomous sailboat. In: A. Friebe, F. Haug (eds.) Robotic Sailing 2015, pp. 3-13. Springer International Publishing (2016). URL https ://doi .org/10.1007/978-3-319-23335-2_1

2. Ghani, M.H., Hole, L.R., Fer, I., Kourafalou, V.H., Wienders, N., Kang, H., Drushka, K., Peddie, D.: The sailbuoy remotely-controlled unmanned vessel: Measurements of near surface temperature, salinity and oxygen concentration in the northern gulf of mexico. Methods in Oceanography 10, $104-121$ (2014). DOI https://doi.org/10.1016/j.mio.2014.08.001. URL http://www.sciencedirect. 
com/science/article/pii/S2211122014000395. Special Issue: Autonomous Marine Vehicles

3. Grothues, T.M., Dobarro, J., Ladd, J., Higgs, A., Niezgoda, G., Miller, D.: Use of a multi-sensored auv to telemeter tagged atlantic sturgeon and map their spawning habitat in the hudson river, usa. In: 2008 IEEE/OES Autonomous Underwater Vehicles, pp. 1-7 (2008). DOI 10.1109/AUV.2008.5347597. URL https://doi. org/10.1109/AUV.2008.5347597

4. Lin, Y., Hsiung, J., Piersall, R., White, C., Lowe, C.G., Clark, C.M.: A multiautonomous underwater vehicle system for autonomous tracking of marine life. Journal of Field Robotics 34(4), 757-774 (2017). DOI 10.1002/rob.21668. URL https://doi.org/10.1002/rob.21668

5. Meyers, Eva K. M., Tuya, Fernando, Barker, Joanna, Jiménez Alvarado, David, Castro-Hernández, José Juan, Haroun, Ricardo, Rödder, Dennis: Population structure, distribution and habitat use of the critically endangered angelshark, squatina squatina, in the canary islands. Aquatic Conservation: Marine and Freshwater Ecosystems 27(6), 1133-1144 (2017). DOI 10.1002/aqc.2769. URL https: //onlinelibrary.wiley.com/doi/abs/10.1002/aqc.2769

6. Mordy, C.W., Cokelet, E.D., De Robertis, A., Jenkins, R., Kuhn, C.E., LawrenceSlavas, N., Berchok, C.L., Crance, J.L., Sterling, J.T., Cross, J.N., Stabeno, P.J., Meinig, C., Tabisola, H.M., Burgess, W., Wangen, I.: Advances in ecosystem research: Saildrone surveys of oceanography, fish, and marine mammals in the bering sea. Oceanography 30 (2017). URL https://doi.org/10.5670/oceanog.2017. 230

7. Morey, G., Barker, J., Hood, A., Gordon, C., Bartolí, A., Meyers, E., Ellis, J., Sharp, R., Jimenez-Alvarado, D., Pollom, R.: Squatina squatina. The IUCN Red List of Threatened Species 2019 e.T39332A117498371 (2019). DOI 10.2305/IUCN.UK.2019-1.RLTS.T39332A117498371.en. URL http://dx.doi. org/10.2305/IUCN.UK.2019-1. RLTS. T39332A117498371.en

8. Santana-Jorge, F.J., Domínguez-Brito, A.C., Cabrera-Gámez, J.: A componentbased c ++ communication middleware for an autonomous robotic sailboat. In: K.I. Øvergård (ed.) Robotic Sailing 2017, pp. 39-54. Springer International Publishing (2018). URL https://doi.org/10.1007/978-3-319-72739-4_4

9. Verfuss, U.K., Aniceto, A.S., Harris, D.V., Gillespie, D., Fielding, S., Jiménez, G., Johnston, P., Sinclair, R.R., Sivertsen, A., Solbø, S.A., Storvold, R., Biuw, M., Wyatt, R.: A review of unmanned vehicles for the detection and monitoring of marine fauna. Marine Pollution Bulletin 140, $17-29$ (2019). DOI https:// doi.org/10.1016/j.marpolbul.2019.01.009. URL http://www. sciencedirect.com/ science/article/pii/S0025326X19300098

10. Voosen, P.: Saildrone fleet could help replace aging buoys. Science 359(6380), 1082-1083 (2018). DOI 10.1126/science.359.6380.1082. URL https://science. sciencemag.org/content/359/6380/1082

11. Zolich, A., Johansen, T.A., Alfredsen, J.A., Kuttenkeuler, J., Erstorp, E.: A formation of unmanned vehicles for tracking of an acoustic fish-tag. In: OCEANS 2017 - Anchorage, pp. 1-6 (2017). URL https://ieeexplore.ieee.org/document/ 8232099 